Psychological Medicine

http://journals.cambridge.org/PSM

Additional services for Psychological Medicine:

PSYCHOLOGICAL

MEDICINE

Email alerts: $\underline{\text { Click here }}$

Subscriptions: $\underline{\text { Click here }}$

Commercial reprints: $\underline{\text { Click here }}$

Terms of use : $\underline{\text { Click here }}$

\title{
Depressive symptom dimensions and cardiac prognosis following myocardial infarction: results from the ENRICHD clinical trial
}

S. Bekke-Hansen, M. Trockel, M. M. Burg and C. Barr Taylor

Psychological Medicine / Volume 42 / Issue 01 / January 2012, pp 51 - 60

DOI: 10.1017/S0033291711001000, Published online: 20 June 2011

Link to this article: http://journals.cambridge.org/abstract_S0033291711001000

How to cite this article:

S. Bekke-Hansen, M. Trockel, M. M. Burg and C. Barr Taylor (2012). Depressive symptom dimensions and cardiac prognosis following myocardial infarction: results from the ENRICHD clinical trial. Psychological Medicine, 42, pp 51-60 doi:10.1017/S0033291711001000

Request Permissions : $\underline{\text { Click here }}$ 


\title{
Depressive symptom dimensions and cardiac prognosis following myocardial infarction: results from the ENRICHD clinical trial
}

\author{
S. Bekke-Hansen ${ }^{1 *}$, M. Trockel ${ }^{2}$, M. M. Burg ${ }^{3,4}$ and C. Barr Taylor ${ }^{2}$ \\ ${ }^{1}$ Department of Psychology, Aarhus University, Aarhus, Denmark \\ ${ }^{2}$ Department of Psychiatry and Behavior Sciences, Stanford University, Stanford, CA, USA \\ ${ }^{3}$ Columbia University Medical Center, New York, NY, USA \\ ${ }^{4}$ Yale University Medical School, New Haven, CT, USA
}

Background. Depression following myocardial infarction (MI) independently increases risk for early cardiac morbidity and mortality. Studies suggest that somatic, but not cognitive, depressive symptoms are responsible for the increased risk. However, the effects of somatic depressive symptoms at follow-up, after sufficient time has elapsed to allow for physical recovery from the initial infarction, are not known. Our aim was to examine the relationship between cognitive and somatic depressive symptom dimensions at baseline and 12 months post-MI and subsequent mortality and cardiovascular morbidity.

Method. Patients were 2442 depressed and/or socially isolated men and women with acute MI included in the Enhancing Recovery in Coronary Heart Disease (ENRICHD) clinical trial. We used principal components analysis (PCA) of the Beck Depression Inventory (BDI) items to derive subscales measuring cognitive and somatic depressive symptom dimensions, and Cox regression with Bonferroni correction for multiple testing to examine the contribution of these dimensions to all-cause mortality, cardiovascular mortality, and first recurrent non-fatal MI.

Results. After adjusting for medical co-morbidity and Bonferroni correction, the somatic depressive symptom dimension assessed proximately following MI did not significantly predict any endpoints. At 12 months post-MI, however, this dimension independently predicted subsequent all-cause [hazard ratio (HR) 1.43, 95\% confidence interval (CI) 1.13-1.81] and cardiovascular mortality (HR 1.60, 95\% CI 1.17-2.18). No significant associations were found between the cognitive depressive symptom dimension and any endpoints after Bonferroni correction.

Conclusions. Somatic symptoms of depression at 12 months post-MI in patients at increased psychosocial risk predicted subsequent mortality. Psychosocial interventions aimed at improving cardiac prognosis may be enhanced by targeting somatic depressive symptoms, with particular attention to somatic symptom severity at 12 months post-MI.

Received 1 January 2011; Revised 11 May 2011; Accepted 14 May 2011; First published online 20 June 2011

Key words: Coronary heart disease, depression, mortality, myocardial infarction, prognosis.

\section{Introduction}

Depression following myocardial infarction (MI) is common (Schleifer et al. 1989; Forrester et al. 1992; Frasure-Smith et al. 1993) and has been associated with a 2- to 2.5-fold increased risk of recurrent non-fatal cardiac events and mortality (Barth et al. 2004; van Melle et al. 2004). Although several mechanisms linking depression to adverse cardiac outcomes have been proposed, the exact mechanisms are not known

* Address for correspondence: S. Bekke-Hansen, M.Sc., Department of Psychology, Aarhus University, Jens Chr. Skous Vej 4, DK-8000 Aarhus, Denmark.

(Email: sidsel@psy.au.dk) (de Jonge et al. 2010). Furthermore, randomized controlled trials (van Melle et al. 2007), including the Enhancing Recovery in Coronary Heart Disease (ENRICHD) trial (Berkman et al. 2003), have not found that treating depression reduces risk for subsequent cardiac events. Given the substantial overlap between symptoms of depression and cardiac disease, it is not clear to what extent the association between post-MI depression and worse cardiac prognosis is confounded by cardiac disease severity (de Jonge et al. 2006a; Martens et al. 2010). For instance, in their metaanalysis, Nicholson et al. (2006) found that almost half of the increased risk of death in depressed coronary heart disease (CHD) patients was accounted for by CHD severity, especially left ventricular ejection 
fraction (LVEF). Some reports have suggested the utility of distinguishing between depressive symptom clusters in modeling cardiovascular prognosis. Three such studies among general CHD populations (de Jonge et al. 2006a; Linke et al. 2009; Martens et al. 2010) used factor analysis to examine the dimensional structure of the Beck Depression Inventory (BDI), resulting in two or three depressive symptom dimensions: cognitive/affective, somatic/affective and appetitive.

de Jonge et al. (2006a) found that, after controlling for LVEF, Killip class and previous MI, only somatic/ affective symptoms predicted cardiovascular mortality in MI patients. Martens et al. (2010) and Linke et al. (2009) replicated this finding in samples of MI patients and in women with suspected myocardial ischemia respectively, and furthermore found appetitive depressive symptoms to be associated with a more adverse cardiac prognosis (Linke et al. 2009). Cognitive/affective depressive symptoms were, however, not related to cardiac prognosis in these studies. Similarly, in a study of chronic heart failure patients, only somatic/affective depressive symptoms were associated with all-cause mortality (Schiffer et al. 2009). In light of the ongoing debate as to whether somatic depressive symptoms are another manifestation of CHD severity, it should be noted that the association between somatic depressive symptoms and cardiac prognosis remained after controlling for cardiac disease severity.

Using data from the ENRICHD clinical trial, our aim was to examine the effects on subsequent prognosis of BDI depressive symptom dimensions at the time of an index MI and at 12-month follow-up in a sample of patients who were depressed and/or socially isolated at baseline. We examined the effects of these symptom dimensions 12 months after the index event to expand our understanding of the link between depression and post-MI prognosis, because transient depressive symptoms at baseline, when patients may be faced with acute adjustment of a major life-threatening event, may influence prognosis differently than depressive symptoms occurring several months after the life-threatening cardiac event. The effects on prognosis of somatic depressive symptoms at follow-up, after sufficient time has elapsed to allow for physical recovery from the initial MI, are not known.

\section{Method}

\section{Study design and participants}

ENRICHD was a National Heart, Lung, and Blood Institute (NHLBI)-funded randomized clinical trial conducted from October 1996 to April 2001 that recruited 2481 patients with acute myocardial infarction (AMI) meeting the study criteria for depression and/or low perceived social support (LPSS). Patients were recruited from 73 hospitals affiliated with eight clinical centers and randomized to a cognitive behavior therapy (CBT) intervention or treatment as usual. The main study objective was to evaluate the effect of intervention, relative to usual care, on the primary endpoint of combined all-cause mortality and recurrent MI. Follow-up assessments were conducted at $6,12,18,30$ and 42 months. Prior to initiation of recruitment, the study protocol was approved by the eight local institutional review boards. The study organization, design, methods and results have been described in detail elsewhere (ENRICHD Investigators, 2000, 2001 $a$; Berkman et al. 2003).

The criteria for AMI were a characteristic increase in at least one biomarker of myocardial injury to twice the upper limit as established within the recruiting institution. Additionally, symptoms compatible with AMI or characteristic evolutionary electrocardiographic ST-T changes or new $Q$ waves had to be present. Moreover, patients undergoing interventions for ST elevation were suitable for inclusion, regardless of the biomarker criteria (ENRICHD Investigators, 2000; Berkman et al. 2003).

Patients were excluded from ENRICHD if they had a non-cardiac illness likely to be fatal within 1 year; were too ill to participate; had major psychiatric co-morbidity (including imminent risk for suicide, schizophrenia, bipolar disorder, severe dementia or current substance abuse); were already receiving psychotherapy for depression; could not be enrolled within 28 days of their cardiac event; were not accessible for follow-up; could not provide informed consent; or were participating in another trial (Berkman et al. 2003).

\section{Psychosocial measures}

\section{Depressive symptoms}

Patients were eligible for the study if they met modified DSM-IV (APA, 1994) diagnostic criteria for dysthymia, minor depressive disorder or major depressive disorder on the Depression Interview and Structured Hamilton (DISH), developed for the ENRICHD trial (Freedland et al. 2002; Berkman et al. 2003). The BDI was also administered to patients as part of the baseline assessment and at follow-up assessments. The BDI is a 21-item questionnaire with each item representing an aspect of the depression clinical presentation and rated on a 0-3-point scale of symptom severity (Beck et al. 1988). BDI scores of 10-15 indicate mild depression, 16-23 moderate depression, and 24-63 severe depression. 


\section{Perceived social support (PSS)}

PSS was assessed with the ENRICHD Social Support Instrument (ESSI), which has been described in detail elsewhere (ENRICHD Investigators, 2000, 2001b). In brief, the ESSI is a five-item questionnaire designed for the ENRICHD trial to assess perceived functional and emotional support. A total score $\leqslant 18$ with a score $\leqslant 3$ on at least two items or a score $\leqslant 2$ on two items regardless of the total score was used to classify patients with LPSS (ENRICHD Investigators, 2000; Berkman et al. 2003).

\section{Sociodemographic and clinical variables}

The baseline variables included in the ENRICHD trial have been described in detail elsewhere (ENRICHD Investigators, 2001b; Watkins et al. 2003; Jaffe et al. 2006). For this secondary analysis, sociodemographic and clinical covariates were selected on the basis of a medical risk model developed from the ENRICHD dataset, and reported previously (Jaffe et al. 2006). Baseline sociodemographic variables included age, gender, ethnicity, marital status, education, and annual household income. We further included information on ejection fraction (EF), previous MI, congestive heart failure $(\mathrm{CHF})$, diabetes, chronic pulmonary disease, malignancy, and renal disease.

\section{Main outcome measures}

The primary endpoint in the ENRICHD trial was a composite of recurrent non-fatal $\mathrm{MI}$ and all-cause mortality. Secondary endpoints included, among others, cardiovascular mortality and cardiovascular hospitalizations (ENRICHD Investigators, 2000). In the present study, endpoints included all-cause mortality, cardiovascular mortality, and first recurrent non-fatal MI. Hospital readmissions and deaths were identified at follow-up visits and through telephone contact with patients and their family (Jaffe et al. 2006). If an event had occurred, supporting documentation from the medical record was obtained and, if necessary, a death certificate (Jaffe et al. 2006). In addition, at the annual follow-up visits, a resting electrocardiogram (ECG) was performed and unrecognized MI was determined by the ECG Core Laboratory. Endpoints were classified according to standardized criteria (Jaffe et al. 2006).

\section{Statistical analyses}

Of the 2481 patients included in the ENRICHD trial, $98.4 \%(n=2442)$ provided BDI information at baseline and were thus included in this secondary analysis. Of these, $72.8 \% \quad(n=1777)$ completed the BDI at
12 months. Of those $(n=665)$ who did not complete the BDI at 12 months, mortality prior to 12 months was confirmed for 233. Differences in sociodemographic, clinical and psychosocial baseline characteristics between responders $(n=1777)$ and non-responders $(n=432)$ at 12 months were examined with an independent-samples $t$ test and $\chi^{2}$ tests for independence, for continuous and categorical variables respectively.

We first established the underlying structure of the BDI for the ENRICHD sample at baseline, using principal components analysis (PCA) with direct oblimin rotation (Field, 2009). An oblique method was chosen over an orthogonal, as the factors were expected to correlate. The contribution of depressive symptom dimensions at baseline and 12 months to subsequent prognosis was determined by Cox regression analysis. We standardized the depression subscale scores for ease of interpretation. The initial model entered baseline cognitive and somatic symptom dimensions simultaneously, with adjustment for treatment assignment (intervention versus usual care). The covariates added to the second model included age, gender, ethnicity, marital status, education, annual household income, and LPSS. Three indicators of cardiac disease severity (LVEF, history of CHF, previous $\mathrm{MI}$ ), were entered in a third model, and pulmonary disease, diabetes, malignancy, and renal disease were added in a fourth model. All of these baseline covariates were included in models testing the effects of 12-month depressive symptom dimensions, controlling for baseline somatic and cognitive symptom dimensions, and for interim cardiac and non-cardiac hospitalizations. To adjust for multiple testing, a Bonferroni correction was applied $(0.05 / 12=0.0042)$. All statistical analyses were performed with SPSS version 18 (SPSS Inc., USA).

\section{Results}

\section{Patient characteristics}

The baseline characteristics of the ENRICHD sample $(n=2481)$ have been described previously (ENRICHD Investigators, 2001b). Selected sociodemographic, clinical and psychosocial baseline characteristics of the present subsample $(n=2442)$ are shown in Table 1 along with differences in baseline characteristics between responders and non-responders at 12 months. Differences were found with respect to gender and minority status.

\section{Factor structure of the BDI}

Bartlett's test of sphericity $(p<0.001)$ and the KaiserMeyer-Olkin measure of sampling adequacy (0.90) 
Table 1. Baseline characteristics of the ENRICHD subsample and differences at baseline between responders and non-responders at 12 months

\begin{tabular}{|c|c|c|c|c|}
\hline Characteristics & $\begin{array}{l}\text { Baseline } \\
(n=2442)\end{array}$ & $\begin{array}{l}\text { Responders at } \\
12 \text { months } \\
(n=1777)\end{array}$ & $\begin{array}{l}\text { Non-responders } \\
\text { at } 12 \text { months } \\
(n=432)\end{array}$ & $\begin{array}{l}p \text { value for } \\
\text { responder versus } \\
\text { non-responder } \\
\text { differences }\end{array}$ \\
\hline \multicolumn{5}{|l|}{ Sociodemographic variables } \\
\hline Male gender & $1372(56.2)$ & $989(55.7)$ & $265(61.3)$ & 0.04 \\
\hline Age (years), mean (s.D.) & $60.8(12.6)$ & $60.2(12.2)$ & $59.9(12.5)$ & 0.68 \\
\hline Non-minority & $1620(66.3)$ & $1192(67.1)$ & $266(61.6)$ & 0.04 \\
\hline Married/partnered & $1265(51.8)$ & $933(52.5)$ & $220(50.9)$ & 0.59 \\
\hline$\leqslant$ High school & $1331(54.5)$ & $942(53.0)$ & $230(53.2)$ & 0.97 \\
\hline Annual household income & & & & 0.26 \\
\hline$<\mathrm{US} \$ 20000$ & $851(34.8)$ & $610(34.3)$ & $149(34.5)$ & \\
\hline$\geqslant$ US $\$ 20000$ and $<$ US\$40 000 & $514(21.0)$ & $394(22.2)$ & $78(18.1)$ & \\
\hline$\geqslant \mathrm{US} \$ 40000$ & $454(18.6)$ & $337(19.0)$ & 89 (20.6) & \\
\hline Unknown & $623(25.5)$ & $436(24.5)$ & $116(26.9)$ & \\
\hline \multicolumn{5}{|l|}{ Clinical variables } \\
\hline Ejection fraction (\% LVEF) & & & & 0.55 \\
\hline $\mathrm{EF}<35 \%$ & $321(13.1)$ & $219(12.3)$ & $50(11.6)$ & \\
\hline $35 \% \leqslant \mathrm{EF}<40 \%$ & $183(7.5)$ & $122(6.9)$ & $27(6.3)$ & \\
\hline $40 \% \leqslant \mathrm{EF}<45 \%$ & $243(10.0)$ & $171(9.6)$ & $47(10.9)$ & \\
\hline $45 \% \leqslant \mathrm{EF}<50 \%$ & $242(9.9)$ & $182(10.2)$ & $42(9.7)$ & \\
\hline $50 \% \leqslant \mathrm{EF}<55 \%$ & $335(13.7)$ & $265(14.9)$ & $53(12.3)$ & \\
\hline $\mathrm{EF} \geqslant 55 \%$ & $641(26.2)$ & $486(27.3)$ & $117(27.1)$ & \\
\hline Unknown & $477(19.5)$ & $332(18.7)$ & $96(22.2)$ & \\
\hline Previous MI & $651(26.7)$ & $429(24.1)$ & $116(26.9)$ & 0.27 \\
\hline History of $\mathrm{CHF}$ & $329(13.5)$ & $187(10.5)$ & $53(12.3)$ & 0.34 \\
\hline Diabetes & $800(32.8)$ & $567(31.9)$ & $134(31.0)$ & 0.77 \\
\hline Chronic pulmonary disease & $450(18.4)$ & $308(17.3)$ & 77 (17.8) & 0.86 \\
\hline Malignancy & $218(8.9)$ & $160(9.0)$ & $31(7.2)$ & 0.26 \\
\hline Renal disease & $238(9.7)$ & $149(8.4)$ & $34(7.9)$ & 0.80 \\
\hline \multicolumn{5}{|l|}{ Psychosocial variables } \\
\hline Intervention & $1225(50.2)$ & $895(50.4)$ & $210(48.6)$ & 0.55 \\
\hline Psychosocial risk group & & & & 0.08 \\
\hline Depressed & $964(39.5)$ & $708(39.8)$ & $148(34.3)$ & \\
\hline LPSS & $632(25.9)$ & $463(26.1)$ & $117(27.1)$ & \\
\hline Depressed/LPSS & $846(34.6)$ & $606(34.1)$ & $167(38.7)$ & \\
\hline
\end{tabular}

ENRICHD, Enhancing Recovery in Coronary Heart Disease trial; LVEF, left ventricular ejection fraction; MI, myocardial infarction; $\mathrm{CHF}$, congestive heart failure ; LPSS, low perceived social support; S.D., standard deviation.

Values given as $n(\%)$ of total unless stated otherwise.

indicated that the data were suitable for PCA. In the initial analysis, four components with eigenvalues above 1 emerged; however, the screeplot revealed a break after the second component, and only two items (loss of appetite and loss of weight) loaded above 0.3 on the third component. This was also the case in a forced three-factor solution, suggesting that a twofactor solution would be appropriate because at least three items per component is advised (Costello \& Osborne, 2005). In the forced two-factor solution, the weight loss item loaded weakly on both components $(-0.08$ and 0.28$)$. Given the problematic contingent scoring of this item, coupled with poor factor loadings, we excluded it from the measurement model. The refined two-factor model provided an acceptable solution, although the irritability item loaded weakly on both components, and the dissatisfaction item loaded above 0.3 on both components. Table 2 shows the pattern and structure matrix of the final two-factor model. The total variance explained by the two-factor 
Table 2. Factor loadings of BDI depressive symptom dimensions ${ }^{a}$

\begin{tabular}{|c|c|c|c|c|}
\hline & \multicolumn{2}{|c|}{ Pattern coefficients } & \multicolumn{2}{|c|}{ Structure coefficients } \\
\hline & Cognitive & Somatic & Cognitive & Somatic \\
\hline Sadness & 0.46 & 0.24 & 0.55 & 0.42 \\
\hline Pessimism & 0.58 & 0.11 & 0.62 & 0.33 \\
\hline Sense of failure & 0.72 & -0.10 & 0.68 & 0.17 \\
\hline Dissatisfaction & 0.36 & 0.33 & 0.49 & 0.47 \\
\hline Guilt & 0.67 & -0.12 & 0.62 & 0.14 \\
\hline Punishment & 0.64 & -0.16 & 0.58 & 0.08 \\
\hline Self-dislike & 0.72 & -0.04 & 0.70 & 0.23 \\
\hline Self-accusations & 0.65 & -0.03 & 0.64 & 0.22 \\
\hline Suicidal thoughts & 0.47 & -0.05 & 0.46 & 0.13 \\
\hline Crying & 0.36 & 0.23 & 0.45 & 0.37 \\
\hline Irritability & 0.26 & 0.24 & 0.35 & 0.33 \\
\hline Social withdrawal & 0.40 & 0.20 & 0.48 & 0.36 \\
\hline Indecisiveness & 0.37 & 0.28 & 0.47 & 0.42 \\
\hline Body image change & 0.45 & 0.11 & 0.49 & 0.28 \\
\hline Work difficulties & -0.10 & 0.74 & 0.18 & 0.70 \\
\hline Insomnia & 0.06 & 0.52 & 0.26 & 0.54 \\
\hline Fatigability & -0.07 & 0.77 & 0.22 & 0.74 \\
\hline Loss of appetite & -0.11 & 0.61 & 0.13 & 0.57 \\
\hline Somatic preoccupation & 0.23 & 0.34 & 0.35 & 0.42 \\
\hline Decreased libido & 0.11 & 0.38 & 0.25 & 0.42 \\
\hline
\end{tabular}

BDI, Beck Depression Inventory.

The highest loadings are in bold.

a Principal components analysis (PCA) with direct oblimin rotation.

model was $33.6 \%$, and the correlation between components was 0.38 , supporting the use of an oblique rotation.

\section{Cognitive and somatic dimensions}

The internal consistency of the BDI cognitive dimension was satisfactory for the baseline $(\alpha=0.82)$ and 12 -month follow-up assessments $(\alpha=0.88)$. Cronbach's $\alpha$ on the somatic dimension at baseline was marginally satisfactory $(\alpha=0.62)$, and satisfactory at the 12-month follow-up $(\alpha=0.76)$. The correlation between subscale scores measuring the two dimensions of depression was moderate at baseline $(r=0.47, p<0.001)$ and strong at the 12-month follow-up $(r=0.68, p<0.001)$. The mean BDI total scale score and symptom dimensions scores at baseline and at the 12-month follow-up are shown in Table 3. At baseline, the mean total scale score corresponded to moderate depressive symptoms, which decreased to mild depressive symptoms at the 12-month follow-up. No differences in baseline cognitive and somatic symptoms of depression were found between those who provided BDI data at 12 months and those who did not.
Table 3. BDI total scale and symptom dimension scores at baseline and 12 months post-MI

\begin{tabular}{lrrr}
\hline & $\begin{array}{l}\text { Total } \\
\text { (21 items) }\end{array}$ & $\begin{array}{l}\text { Cognitive } \\
\text { (14 items) }\end{array}$ & $\begin{array}{l}\text { Somatic } \\
\text { (6 items) }\end{array}$ \\
\hline Baseline & $15.8(8.4)$ & $8.5(6.1)$ & $6.6(3.4)$ \\
12-month follow-up & $9.3(8.9)$ & $5.0(5.9)$ & $4.0(3.5)$
\end{tabular}

BDI, Beck Depression Inventory; MI, myocardial infarction.

Values given as mean (standard deviation).

\section{Depressive symptom dimensions and cardiovascular prognosis}

The mean follow-up time was 2.3 years for all-cause and cardiovascular mortality, and 2.1 years for non-fatal MI. A total of 335 patients died during the follow-up period and $62.4 \%$ (209) were classified as cardiovascular deaths. In addition, 336 patients experienced recurrent non-fatal MI. The number of events before and after 12 months is shown in Table 4 . A total of 639 cardiovascular hospitalizations and 624 non-cardiovascular hospitalizations occurred within 
Table 4. Number of events before and after 12 months

\begin{tabular}{llll}
\hline & \multicolumn{3}{l}{ Number of events (\% of total) } \\
\cline { 2 - 4 } & $\begin{array}{l}\text { All-cause } \\
\text { mortality }\end{array}$ & $\begin{array}{l}\text { CV } \\
\text { mortality }\end{array}$ & $\begin{array}{l}\text { Non-fatal } \\
\text { MI }\end{array}$ \\
Time period & Total=335 & Total=209 & Total=336 \\
\hline Baseline to 12 months & $233(69.6)$ & $145(69.4)$ & $243(72.3)$ \\
After 12 months & $102(30.4)$ & $64(30.6)$ & $93(27.7)$ \\
\hline
\end{tabular}

$\mathrm{CV}$, Cardiovascular; MI, myocardial infarction.

the first 12 months. The results from Cox regression analyses on depressive symptom dimensions and subsequent outcomes are shown in Table 5.

\section{Somatic and cognitive symptoms of depression at baseline}

The associations between the somatic depressive symptom dimension at baseline and all-cause mortality, cardiovascular mortality and recurrent non-fatal MI were statistically significant when adjusting for treatment group. The effect on cardiovascular mortality became non-significant when additionally adding sociodemographic variables and co-morbid LPSS to the model, as did all-cause mortality with the further addition of cardiac disease severity. The effect of somatic depressive symptoms on subsequent nonfatal MI became non-significant in the fully adjusted model. The baseline cognitive depressive symptom dimension was associated with all-cause mortality when adjusting for treatment group; however, this effect was not statistically significant in the subsequent adjusted model.

\section{Somatic and cognitive symptoms of depression at the 12-month follow-up}

The somatic depressive symptom dimension at 12 months predicted all-cause and cardiovascular mortality after adjusting for baseline depressive symptom dimensions and all other covariates, including interim cardiovascular and non-cardiovascular hospitalizations. An increase in score of one standard deviation on the somatic subscale predicted a $43 \%$ increase in risk of all-cause mortality and a $60 \%$ increase in risk of cardiovascular mortality whereas no significant associations were found for non-fatal MI. Subsequent outcomes were not significantly predicted by the cognitive depressive symptom dimension at 12 months.

\section{Discussion}

Contrary to our expectations, when adjusting for sociodemographic factors, cardiac disease severity and comorbidity, somatic depressive symptoms measured at the time of the index cardiac event were not associated with cardiac morbidity or mortality. However, somatic depressive symptoms 12 months post-MI were associated with all-cause and cardiovascular mortality. Cognitive depressive symptoms were found to be unrelated to prognosis in all fully adjusted models after Bonferroni correction; however, a non-significant trend was found for cognitive depressive symptoms at 12 months predicting lower cardiovascular mortality.

Our finding that baseline post-MI somatic depressive symptoms did not predict prognosis differs from the results of several prior studies (de Jonge et al. 2006a; Linke et al. 2009; Schiffer et al. 2009; Smolderen et al. 2009; Hoen et al. 2010; Martens et al. 2010; Roest et al. 2011) demonstrating a significant effect of baseline somatic depressive symptoms on cardiac prognosis. Differences between the present study and previous studies with respect to sample composition, included covariates, and factor analytic solutions may in part explain these inconsistencies. Furthermore, the timing of the baseline depression assessment may have influenced our results. In their meta-analysis, Nicholson et al. (2006) found that depression assessed more than 2 weeks after an MI showed a stronger association with cardiac prognosis than depression assessed closer to the event. In the ENRICHD trial, patients were enrolled an average of 11 days post-MI (Jaffe et al. 2006), making it plausible that some initial depressive symptoms were transient.

Most prior studies (Linke et al. 2009; Smolderen et al. 2009; Hoen et al. 2010; Martens et al. 2010; Roest et al. 2011) have not found a significant association between cognitive depressive symptoms and cardiac prognosis; however, one recent study demonstrated that a cognitive depressive symptom dimension marked by pessimism, past failure, self-criticalness and worthlessness predicted cardiac morbidity and mortality (Tully et al. 2011). Although cognitive symptoms were not significant predictors of post-MI prognosis in the current study, after Bonferroni correction, one prior study found a protective effect of cognitive depressive symptoms on cardiovascular mortality (de Jonge et al. 2006a). The authors of that study concluded that the effect estimate for cognitive symptoms was being overcorrected by statistical control for somatic depressive symptoms. It is possible that their finding was not spurious and that our conservative use of Bonferroni criteria resulted in failure to demonstrate an association between cognitive symptoms of depression and improved prognosis. However, we can offer only speculative hypotheses regarding mechanisms to explain this association and instead focus our discussion on the findings that were significant in the current study. 
Table 5. Results from Cox regression analyses: depressive symptom dimensions at baseline and 12-month follow-up and subsequent outcomes

\begin{tabular}{|c|c|c|c|c|c|c|}
\hline & \multicolumn{6}{|c|}{ Main outcome measures } \\
\hline & \multicolumn{2}{|c|}{ All-cause mortality } & \multicolumn{2}{|l|}{ CV mortality } & \multicolumn{2}{|l|}{ Non-fatal MI } \\
\hline & $\operatorname{HR}(95 \% \mathrm{CI})$ & $p$ value ${ }^{\mathrm{a}}$ & HR $(95 \%$ CI) & $p$ value $^{\mathrm{a}}$ & $\operatorname{HR}(95 \% \mathrm{CI})$ & $p$ value ${ }^{\mathrm{a}}$ \\
\hline \multicolumn{7}{|l|}{ Baseline } \\
\hline \multicolumn{7}{|l|}{ Model $1^{\mathrm{b}}$} \\
\hline Cognitive & $0.79(0.70-0.90)$ & $<0.001$ & $0.84(0.72-0.98)$ & 0.03 & $1.00(0.90-1.13)$ & 0.94 \\
\hline Somatic & $1.41(1.26-1.58)$ & $<0.001$ & $1.36(1.18-1.58)$ & $<0.001$ & $1.30(1.16-1.46)$ & $<0.001$ \\
\hline \multicolumn{7}{|l|}{ Model $2^{c}$} \\
\hline Cognitive & $0.94(0.83-1.07)$ & 0.38 & $0.99(0.84-1.16)$ & 0.85 & $1.05(0.93-1.18)$ & 0.44 \\
\hline Somatic & $1.24(1.10-1.40)$ & 0.001 & $1.21(1.03-1.41)$ & 0.02 & $1.25(1.10-1.41)$ & $<0.001$ \\
\hline \multicolumn{7}{|l|}{ Model $3^{\mathrm{d}}$} \\
\hline Cognitive & $0.95(0.84-1.09)$ & 0.46 & $1.00(0.85-1.18)$ & 0.99 & $1.05(0.93-1.18)$ & 0.46 \\
\hline Somatic & $1.14(1.01-1.29)$ & 0.04 & $1.09(0.93-1.28)$ & 0.27 & $1.21(1.07-1.37)$ & 0.003 \\
\hline \multicolumn{7}{|l|}{ Model $4^{\mathrm{e}}$} \\
\hline Cognitive & $0.93(0.82-1.06)$ & 0.30 & $0.98(0.83-1.16)$ & 0.83 & $1.05(0.93-1.18)$ & 0.46 \\
\hline Somatic & $1.09(0.96-1.24)$ & 0.18 & $1.05(0.89-1.23)$ & 0.56 & $1.16(1.03-1.32)$ & 0.02 \\
\hline \multicolumn{7}{|l|}{12 months } \\
\hline \multicolumn{7}{|l|}{ Model $5^{f}$} \\
\hline Cognitive & $0.85(0.66-1.11)$ & 0.23 & $0.66(0.45-0.95)$ & 0.03 & $1.17(0.89-1.52)$ & 0.26 \\
\hline Somatic & $1.49(1.18-1.88)$ & 0.001 & $1.64(1.21-2.23)$ & 0.002 & $1.05(0.79-1.40)$ & 0.74 \\
\hline \multicolumn{7}{|l|}{ Model $6^{\mathrm{g}}$} \\
\hline Cognitive & $0.87(0.67-1.13)$ & 0.30 & $0.66(0.45-0.98)$ & 0.04 & $1.16(0.89-1.52)$ & 0.27 \\
\hline Somatic & $1.43(1.13-1.81)$ & 0.003 & $1.60(1.17-2.18)$ & 0.003 & $1.05(0.79-1.41)$ & 0.73 \\
\hline
\end{tabular}

$\mathrm{CV}$, Cardiovascular; $\mathrm{MI}$, myocardial infarction; $\mathrm{HR}$, hazard ratio; $\mathrm{CI}$, confidence interval.

${ }^{a}$ Bonferroni correction for multiple testing $(\alpha<0.0042)$.

${ }^{\mathrm{b}}$ Adjusted for treatment group.

${ }^{c}$ Adjusted additionally for age, gender, ethnicity, marital status, education, household income, and low perceived social support (LPSS).

d Adjusted additionally for history of congestive heart failure (CHF), ejection fraction (EF), and previous MI.

e Adjusted additionally for pulmonary disease, diabetes, malignancy, and renal disease.

${ }^{\mathrm{f}}$ Depressive symptoms at 12 months adjusted for somatic and cognitive depressive symptoms at baseline, treatment group, age, gender, ethnicity, marital status, education, household income, LPSS, history of CHF, EF, previous MI, pulmonary disease, diabetes, malignancy, and renal disease.

${ }^{\mathrm{g}}$ Depressive symptoms at 12 months adjusted for all baseline variables in the previous model, and for $\mathrm{CV}$ and non-CV hospitalizations occurring between baseline and the 12-month follow-up.

Our findings suggest that somatic depressive symptoms 12 months following MI may be more predictive of post-MI prognosis than somatic depressive symptoms measured close to the acute event. Although the present analyses do not distinguish between pre-existing and new-onset depression, other studies have suggested that new-onset rather than pre-MI depression predicts subsequent adverse cardiac events (Grace et al. 2005; de Jonge et al. 2006b; Dickens et al. 2008).

\section{Possible mechanisms}

Several mechanisms by which depression might increase cardiovascular disease (CVD) risk have been proposed (Lett et al. 2004; de Jonge et al. 2010) and it is possible that somatic depressive symptoms may highlight specific mechanisms. Consistent with this hypothesis, de Jonge et al. (2007) found that somatic symptoms of depression (such as fatigue and psychomotor changes) were associated with reduced heart rate variability, a risk factor for CVD, whereas cognitive symptoms (such as negative self-image) were not. Patients with a more severe depression, which is often accompanied by somatic symptoms, have evidence of hypercortisolemia, which also increases CVD risk (Gillespie \& Nemeroff 2005). Some types of depression may be secondary to underlying cerebrovascular disease, which may be greater in patients with heart disease (Sheline et al. 2010). In previous reports, de Jonge 
et al. (2010) and others (Gold \& Chrousos, 2002; Schiffer et al. 2009) have argued that different subtypes of depression may have different risks. Recently, Davidson et al. (2010) reported that anhedonia (loss of interest or pleasure in all or most activities), but not depressed mood, was an independent predictor of adverse cardiac events and mortality. Anhedonia has been associated with perturbations in sleep, appetite, weight and libido in psychiatric patients (Davidson et al. 2010), and our results are consistent with those findings. In addition, somatic depressive symptoms may reflect an entirely different disease process, such as sleep apnea (Takama \& Kurabayashi, 2009). Thus, a range of factors may underlie the current finding.

\section{Implications for clinical practice}

The ENRICHD intervention improved depression but failed to improve event-free survival (Berkman et al. 2003). The present results suggest that psychosocial interventions directed at improving cardiac prognosis may be enhanced by targeting post-recovery somatic depressive symptoms. The ENRICHD intervention lasted for up to 6 months and interventions of longer duration might be considered in patients with persistent somatic symptoms. Although psychosocial interventions aimed at cognitive symptoms of depression are not likely to improve post-MI prognosis, quality of life, independent of cardiovascular prognosis, may be enhanced by such interventions through improved mood and psychosocial functioning.

\section{Limitations}

The present study relied on secondary analyses of the ENRICHD data. Consequently, the data analyses were bounded by the design of the ENRICHD trial. Given the comprehensive collection of data in the ENRICHD trial, sufficient information was available to test the present hypotheses. However, it should be noted that the ENRICHD sample was limited to post-MI patients at increased psychosocial risk at baseline, and our results may not therefore be generalizable to post-MI patients who are neither depressed nor socially isolated. Of the medically eligible patients in the ENRICHD trial $(n=9279)$, a total of $35 \%$ were depressed and/or socially isolated (ENRICHD Investigators, 2001b). Based on these findings, it is estimated that the present findings would apply to approximately one-third of AMI patients. In addition, approximately half of the ENRICHD participants received CBT. Although the intervention did not improve event-free survival, depressive symptoms were improved in the intervention group (Berkman et al.
2003). We took this into account by controlling for the treatment group status.

In the 12-month models we used interim cardiovascular and non-cardiovascular hospitalizations as a proxy for worsening cardiac disease severity and comorbidity. Although this seems a reasonable proxy, and we did adjust for baseline CVD severity and medical co-morbidity, some patients may have experienced a worsening of their CVD and other comorbid diseases without being hospitalized. Thus, the findings in the 12-month models could have been confounded to some extent by disease severity. Moreover, we were not able to distinguish between pre-MI and post-MI depressive symptoms based on our present analyses. Future studies could benefit from taking this distinction into account.

\section{Conclusions}

The present secondary analyses of ENRICHD data are the first to examine the association between depressive symptom dimensions at 12 months post-MI and subsequent medical prognosis. Somatic depression symptom severity at baseline among post-MI patients who were depressed and/or socially isolated at baseline was not a significant predictor of cardiac morbidity and mortality. By contrast, somatic depressive symptoms at 12 months post-MI were associated with increased all-cause and cardiovascular mortality. These findings suggest that psychosocial interventions aimed at improving cardiac prognosis may be enhanced by targeting somatic depressive symptoms, with particular attention to somatic symptom severity several months post-MI.

\section{Acknowledgments}

This study was supported by contracts NO1-HC55140, NO1-HC-55141, NO1-HC-55142, NO1-HC55143, NO1-HC-55144, NO1-HC-55145, NO1-HC-55146, NO1-HC-55147, and NO1-HC-55148 from the National Heart, Lung, and Blood Institute, National Institutes of Health, Bethesda, MD; grant T32 5 MH09938-15 from the National Institute of Mental Health; and grants from the FOOD Study Group and the Danish Ministry of Food, Agriculture and Fisheries, the Augustinus Foundation, and the Oticon Foundation.

\section{Declaration of Interest}

None.

\section{References}

APA (1994). Diagnostic and Statistical Manual of Mental Disorders, 4th edn. American Psychiatric Association: Washington, DC. 
Barth J, Schumacher M, Herrmann-Lingen C (2004). Depression as a risk factor for mortality in patients with coronary heart disease: a meta-analysis. Psychosomatic Medicine 66, 802-813.

Beck AT, Steer RA, Garbin MG (1988). Psychometric properties of the Beck Depression Inventory: twenty-five years of evaluation. Clinical Psychology Review 8, 77-100.

Berkman LF, Blumenthal J, Burg M, Carney RM, Catellier D, Cowan MJ, Czajkowski SM, DeBusk R, Hosking J, Jaffe A, Kaufmann PG, Mitchell P, Norman J, Powell LH, Raczynski JM, Schneiderman N; Enhancing Recovery in Coronary Heart Disease Patients Investigators (ENRICHD) (2003). Effects of treating depression and low perceived social support on clinical events after myocardial infarction: the Enhancing Recovery in Coronary Heart Disease Patients (ENRICHD) Randomized Trial. Journal of the American Medical Association 289, 3106-3116.

Costello AB, Osborne JW (2005). Best practices in exploratory factor analysis: four recommendations for getting the most from your analysis. Practical Assessment, Research E Evaluation 10 (http:/ / pareonline.net/pdf/ v10n7.pdf).

Davidson KW, Burg MM, Kronish IM, Shimbo D, Dettenborn L, Mehran R, Vorchheimer D, Clemow L, Schwartz JE, Lespérance F, Rieckmann N (2010). Association of anhedonia with recurrent major adverse cardiac events and mortality 1 year after acute coronary syndrome. Archives of General Psychiatry 67, 480-488.

de Jonge P, Mangano D, Whooley MA (2007). Differential association of cognitive and somatic depressive symptoms with heart rate variability in patients with stable coronary heart disease: findings from the Heart and Soul Study. Psychosomatic Medicine 69, 735-739.

de Jonge P, Ormel J, van den Brink RH, van Melle JP, Spijkerman TA, Kuijper A, van Veldhuisen DJ, van den Berg MP, Honig A, Crijns HJ, Schene AH (2006a). Symptom dimensions of depression following myocardial infarction and their relationship with somatic health status and cardiovascular prognosis. American Journal of Psychiatry 163, 138-144.

de Jonge P, Rosmalen JG, Kema IP, Doornbos B, van Melle JP, Pouwer F, Kupper N (2010). Psychophysiological biomarkers explaining the association between depression and prognosis in coronary artery patients: a critical review of the literature. Neuroscience and Biobehavioral Reviews 35, 84-90.

de Jonge P, van den Brink RH, Spijkerman TA, Ormel J

$(2006 b)$. Only incident depressive episodes after myocardial infarction are associated with new cardiovascular events. Journal of the American College of Cardiology 48, 2204-2208.

Dickens C, McGowan L, Percival C, Tomenson B, Cotter L, Heagerty A, Creed F (2008). New onset depression following myocardial infarction predicts cardiac mortality. Psychosomatic Medicine 70, 450-455.

ENRICHD Investigators (2000). Enhancing Recovery in Coronary Heart Disease Patients (ENRICHD) : study design and methods. American Heart Journal 139, 1-9.
ENRICHD Investigators (2001a). Enhancing Recovery in Coronary Heart Disease (ENRICHD) study intervention: rationale and design. Psychosomatic Medicine 63, 747-755.

ENRICHD Investigators (2001b). Enhancing Recovery in Coronary Heart Disease (ENRICHD) : baseline characteristics. American Journal of Cardiology 88, 316-322.

Field A (2009). Discovering Statistics Using SPSS, 3rd edn. SAGE Publications: London.

Forrester AW, Lipsey JR, Teitelbaum ML, DePaulo JR, Andrzejewski PL (1992). Depression following myocardial infarction. International Journal of Psychiatry in Medicine 22, 33-46.

Frasure-Smith N, Lespérance F, Talajic M (1993). Depression following myocardial infarction: impact on 6-month survival. Journal of the American Medical Association 270, 1819-1825.

Freedland KE, Skala JA, Carney RM, Raczynski JM, Taylor CB, Mendes de Leon CF, Ironson G, Youngblood ME, Krishnan KR, Veith RC; ENRICHD Investigators (2002). The Depression Interview and Structured Hamilton (DISH) : rationale, development, characteristics, and clinical validity. Psychosomatic Medicine 64, 897-905.

Gillespie CF, Nemeroff CB (2005). Hypercortisolemia and depression. Psychosomatic Medicine 67, S26-S28.

Gold PW, Chrousos GP (2002). Organization of the stress system and its dysregulation in melancholic and atypical depression: high vs low CRH/NE states. Molecular Psychiatry 7, 254-275.

Grace SL, Abbey SE, Kapral MK, Fang J, Nolan RP, Stewart DE (2005). Effect of depression on five-year mortality after an acute coronary syndrome. American Journal of Cardiology 96, 1179-1185.

Hoen PW, Whooley MA, Martens EJ, Na B, van Melle JP, de Jonge $\mathbf{P}$ (2010). Differential associations between specific depressive symptoms and cardiovascular prognosis in patients with stable coronary heart disease. Journal of the American College of Cardiology 56, 838-844.

Jaffe AS, Krumholz HM, Catellier DJ, Freedland KE, Bittner V, Blumenthal JA, Calvin JE, Norman J, Sequeira R, O'Connor C, Rich MW, Sheps D, Wu C; Enhancing Recovery in Coronary Heart Disease Patients (ENRICHD) Trial Investigators (2006). Prediction of medical morbidity and mortality after acute myocardial infarction in patients at increased psychosocial risk in the Enhancing Recovery in Coronary Heart Disease Patients (ENRICHD) study. American Heart Journal 152, 126-135.

Lett HS, Blumenthal JA, Babyak MA, Sherwood A, Strauman T, Robins C, Newman MF (2004). Depression as a risk factor for coronary artery disease: evidence, mechanisms, and treatment. Psychosomatic Medicine 66, 305-315.

Linke SE, Rutledge T, Johnson BD, Vaccarino V, Bittner V, Cornell CE, Eteiba W, Sheps DS, Krantz DS, Parashar S, Bairey Merz CN (2009). Depressive symptom dimensions and cardiovascular prognosis among women with suspected myocardial ischemia: a report from the National Heart, Lung, and Blood Institute-sponsored Women's 
Ischemia Syndrome Evaluation. Archives of General Psychiatry 66, 499-507.

Martens EJ, Hoen PW, Mittelhaeuser M, de Jonge P, Denollet J (2010). Symptom dimensions of post-myocardial infarction depression, disease severity and cardiac prognosis. Psychological Medicine 40, 807-814.

Nicholson A, Kuper H, Hemingway H (2006). Depression as an aetiologic and prognostic factor in coronary heart disease: a meta-analysis of 6362 events among 146538 participants in 54 observational studies. European Heart Journal 27, 2763-2774.

Roest AM, Thombs BD, Grace SL, Stewart DE, Abbey SE, de Jonge P (2011). Somatic/affective symptoms, but not cognitive/affective symptoms, of depression after acute coronary syndrome are associated with 12-month all-cause mortality. Journal of Affective Disorders 131, 158-163.

Schiffer AA, Pelle AJ, Smith OR, Widdershoven JW, Hendriks EH, Pedersen SS (2009). Somatic versus cognitive symptoms of depression as predictors of all-cause mortality and health status in chronic heart failure. Journal of Clinical Psychiatry 70, 1667-1673.

Schleifer SJ, Macari-Hinson MM, Coyle DA, Slater WR, Kahn M, Gorlin R, Zucker HD (1989). The nature and course of depression following myocardial infarction. Archives of Internal Medicine 149, 1785-1789.

Sheline YI, Pieper CF, Barch DM, Welsh-Boehmer K, McKinstry RC, MacFall JR, D'Angelo G, Garcia KS, Gersing K, Wilkins C, Taylor W, Steffens DC, Krishnan RR, Doraiswamy PM (2010). Support for the vascular depression hypothesis in late-life depression: results of a 2-site, prospective, antidepressant treatment trial. Archives of General Psychiatry 67, 277-285.
Smolderen KG, Spertus JA, Reid KJ, Buchanan DM, Krumholz HM, Denollet J, Vaccarino V, Chan PS (2009). The association of cognitive and somatic depressive symptoms with depression recognition and outcomes after myocardial infarction. Circulation: Cardiovascular Quality and Outcomes 2, 328-337.

Takama N, Kurabayashi M (2009). Influence of untreated sleep-disordered breathing on the long-term prognosis of patients with cardiovascular disease. American Journal of Cardiology 103, 730-734.

Tully PJ, Winefield HR, Baker RA, Turnbull DA, de Jonge P (2011). Confirmatory factor analysis of the Beck Depression Inventory-II and the association with cardiac morbidity and mortality after coronary revascularization. Journal of Health Psychology 16, 584-595.

van Melle JP, de Jonge P, Honig A, Schene AH, Kuyper AM, Crijns HJ, Schins A, Tulner D, van den Berg MP, Ormel J; MIND-IT investigators (2007). Effects of antidepressant treatment following myocardial infarction. British Journal of Psychiatry 190, 460-466.

van Melle JP, de Jonge P, Spijkerman TA, Tijssen JG, Ormel J, van Veldhuisen DJ, van den Brink RH, van den Berg MP (2004). Prognostic association of depression following myocardial infarction with mortality and cardiovascular events: a meta-analysis. Psychosomatic Medicine 66, 814-822.

Watkins LL, Schneiderman N, Blumenthal JA, Sheps DS, Catellier D, Taylor CB, Freedland KE; ENRICHD Investigators (2003). Cognitive and somatic symptoms of depression are associated with medical comorbidity in patients after acute myocardial infarction. American Heart Journal 146, 48-54. 